\title{
ADSORPTION OF HEXAVALENT URANIUM ON DUNITE
}

\section{KONSTANTINOU \\ A. DEMETRIOU I. PASHALIDIS*}

Received: $17 / 11 / 06$

Accepted: 02/04/07
Department of Chemistry, University of Cyprus

P.O. Box 20537, 1678 Lefkosia, Cyprus

*to whom all correspondence should be addressed: e-mail: pspasch@ucy.ac.cy

\begin{abstract}
Pollution of the environment with uranium and associated health effects to human have recently become of major concern, particularly due to the use of depleted uranium in armourbreaking bullets. Indeed, uranium in environmentally significant concentrations is found near to uranium mining and processing facilities and usually involves large volumes of wastewater. Removal of uranium from such large volumes of wastewaters will require a cost effective remediation technology. Conventional wastewater treatment technologies usually rely on mineral adsorbents and chemical flocculating agents. On the other hand chemical behaviour and migration of uranium species in the geosphere is strongly governed by adsorption/desorption phenomena on the underlying rock formations. Hence, studies regarding uranium adsorption on natural minerals and the evaluation of the corresponding thermodynamic data is of fundamental importance with respect to the treatment of contaminated waters and uranium migration in the geosphere.

The present paper reports about the adsorption of hexavalent uranium on dunite at various experimental conditions (e.g. uranium concentration, amount of adsorbent, ionic strength, $\mathrm{pH}$, temperature and contact time) and discusses the effect of these parameters on uranium adsorption. Evaluation of the experimental data shows that the optimum $\mathrm{pH}$ regarding uranium adsorption on dunite is about 6.5. The experimental adsorption data are well fitted by the langmuir isotherm and there is a linear correlation between adsorbent mass and amount of uranium, indicating on the formation of inner-sphere complexes. Moreover, adsorption experiments at various temperatures indicate on a spontaneous, entropy-driven processes and kinetic measurements show that the adsorption process follows a first order rate expression.
\end{abstract}

KEYWORDS: Uranium, Dunite, Sorption, Isotherms, Thermodynamics.

\section{INTRODUCTION}

Uranium, a toxic and weak radioactive heavy metal, is relatively widespread in the environment, and as a naturally occurring element it is found at low levels in virtually all rocks, soils and waters (Shawky et al., 2005). Increased amounts of uranium in the biosphere originate from mining, beneficiation of uranium ores and various processes related to the production of nuclear reactor fuel as well as the use of depleted uranium (DU) in civil and military applications (Bleise et al., 2003). Uranium is of fundamental importance in the nuclear fuel cycle, where it starts as a source and ends up as a final waste component. Pollution of the environment with uranium and associated health effects to human have recently become of major concern, particularly due to the use of DU in armour-breaking bullets. Nevertheless, uranium in environmentally relevant concentrations is found near to uranium mining and processing facilities and usually involves large volumes of wastewater. In aquatic solutions and aquifers uranium exists predominantly in its hexavalent oxidation state e.g. $\mathrm{UO}_{2}{ }^{2+}$. 
Hexavalent uranium is highly mobile and migrates basically in the form of very stable carbonate complexes under near surface conditions (Kilincarslan and Akyil, 2005).

Removal of uranium from large volumes of wastewaters requires a cost effective remediation technology. Several methods are utilized to remove uranium from wastewater and process effluents. These include reduction followed by chemical precipitation, ion exchange, reduction, electrochemical precipitation, solvent extraction, membrane separation, biosorption etc. However, these technologies are both costly and ineffective, particularly when the concentration of uranium is a very low (Blazquez et al., 2005). Adsorption of uranium on mineral adsorbents is an effective and versatile method for removing uranium. Up to now, numerous experimental studies on uranium adsorption on various minerals and rocks have been published (Kilincarslan and Akyil, 2005; Waite et al., 1994; Ames et al., 1983; Aksoyoglu, 1989; Wersin et al., 1994; Donat and Aytas, 2005; Arnold et al., 1998; Zuyi et al., 2000; Zhijun et al., 2004; Hongxia and Zuyi, 2002).

This study is focused on uranium adsorption on dunite, which is a very abundant mineral. Dunite is an igneous, plutonic rock, of ultramafic composition, with coarse grained or phaneritic texture. The mineral assemblage is typically greater than $90 \%$ olivine with minor pyroxene and chromite. Dunite is the olivine rich end member of the peridotite group of mantle-derived rocks. The present paper reports about the adsorption of hexavalent uranium on dunite at various experimental conditions (e.g. uranium concentration, amount of adsorbent, $\mathrm{pH}$, temperature and contact time) and discusses the effect of these parameters on uranium adsorption.

\section{EXPERIMENTAL}

A periodically mixed batch technique was selected for the batch adsorption experiments. All experiments were carried out under normal atmospheric conditions at $25 \pm 1{ }^{\circ} \mathrm{C}$. Test solutions were prepared by dissolution of uranyl nitrate $\left(\mathrm{UO}_{2}\left(\mathrm{NO}_{3}\right)_{2} 6 \mathrm{H}_{2} \mathrm{O}, 99.99 \%\right.$, Merck Co) in aqueous solution. The ionic strength $(0.1 \mathrm{M}$ and $1.0 \mathrm{M})$ in the test solutions was adjusted by addition of sodium perchlorate $\left(\mathrm{NaClO}_{4}\right.$, Aldrich $\left.\mathrm{Co}\right)$. Solutions without background electrolyte (electrolyte-free solutions) are denoted by $\mathrm{I}=0.0 \mathrm{M}$. Dunite used in this study originated from a mountainous area of Cyprus (Troodos massif). Prior application the material was sieved and the particle fraction of 80 mesh was selected for the adsorption experiments and was used without any further purification or other pre-treatment. The BET surface area of the adsorbent (granulated material) was measured by $\mathrm{N}_{2}$-adsorption (Micromeritics $\mathrm{Co}$, ASAP 2000) and has shown that dunite has small internal surface $\left(5.7 \mathrm{~m}^{2} \mathrm{~g}^{-1}\right)$, indicating that adsorption of uranium occurs on its external surface. Further characterization of the material was done using FTIR (8000 Series, Shimadzu), XRD (6000, Shimadzu) and XRF (Spectrace, Shimadzu).

Immediately after the addition of $100 \mathrm{ml}$ of the test solutions to the adsorbent, the bottles were shaken and left to reach equilibrium. During the equilibration period the bottles with the test solutions were shaken regularly. Following three days equilibration, the solutions were first centrifuged at $5000 \mathrm{rpm}$ (Lab centrifuge, Memmert Co), then passed through a 0.45- $\mu \mathrm{m}$ Millex filter (Type GV) and the concentration of uranium in solution was determined by spectrophotometry by means of arsenazo III (Savvin, 1961).

To investigate the effect of various parameters (e.g. pH, initial uranium concentration, amount of adsorbent etc.) on uranium adsorption, five different classes of experiments were conducted. In these experiments the parameter under investigation was varied while other experimental parameters were kept constant. The effect of $\mathrm{pH}$ was studied in an adsorption system $\left(0.05 \mathrm{~g}\right.$ adsorbent and $100 \mathrm{ml}$ of the test solution: $\left.[\mathrm{U}(\mathrm{VI})]=1 \times 10^{-5} \mathrm{~mol} \mathrm{I}^{-1}\right)$ in which $\mathrm{pH}$ was varied between 2 and 12 by addition of $\mathrm{HClO}_{4}$ or $\mathrm{NaOH}$. For studying the effect of initial uranium concentration, the latter was varied between $7.5 \times 10^{-5} \mathrm{~mol} \mathrm{I}^{-1}$ and $5 \times 10^{-6} \mathrm{~mol} \mathrm{I}^{-1}$, at a prefixed amount of adsorbent (adsorbent dosage $=0.05 \mathrm{~g}$ per $100 \mathrm{ml}$ ). The effect of the amount of dunite was investigated by adding different amounts of adsorbent (between 0.0005 and $0.1 \mathrm{~g}$ ) into a $125-\mathrm{ml}$ polyethylene screw capped bottle, containing $100 \mathrm{ml}$ test solutions of constant uranium concentration $\left(1 \times 10^{-5} \mathrm{~mol} \mathrm{I}^{-1}\right)$. 
The effect of temperature was studied between 25 and $70{ }^{\circ} \mathrm{C}$ and measurements were carried out after an equilibration time of three days. The amount of adsorbent $\left(0.5 \mathrm{~g} \mathrm{I}^{-1}\right)$, initial uranium concentration $\left(1 \times 10^{-5} \mathrm{~mol} \mathrm{I}^{-1}\right)$ and $\mathrm{pH}$ in the test solutions $(100 \mathrm{ml})$ were kept constant. For kinetic studies certain amount of dunite $\left(0.5 \mathrm{~g} \mathrm{I}^{-1}\right)$ was mixed with uranium solution $\left(1 \times 10^{-5} \mathrm{~mol}^{-1}\right)$. Samples withdrawn at time intervals were centrifuged and the uranium concentration was determined by photometry.

\section{RESULTS}

\section{The effect of $\mathrm{pH}$}

The $\mathrm{pH}$ of an aqueous solution is an important parameter that governs the adsorption of metal ions on mineral surfaces. Variation in $\mathrm{pH}$ affects speciation and stability of soluble species as well as surface properties (e.g. the charge of functional groups responsible for surface sorption). Figure 1 shows the effect of $\mathrm{pH}$ (in the range between 2 and 12) on the $\mathrm{K}_{d}$ value and hence on the uranium removal by adsorption on dunite.

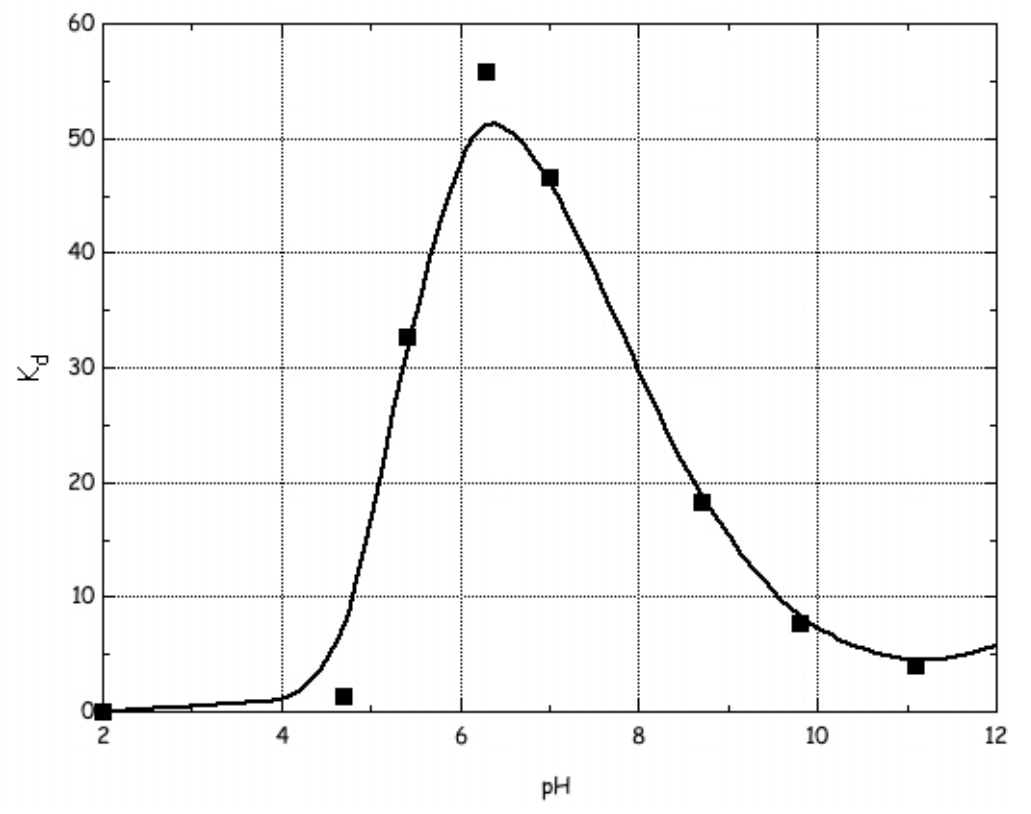

Figure 1. $\mathrm{K}_{\mathrm{d}}$ values as a function of $\mathrm{pH}$ for the uranium adsorption onto dunite at $\mathrm{I}=0.1 \mathrm{M}$

According to Figure 1, increased proton concentration leads to gradual protonation of the surface groups and destabilization of the surface adsorbed uranium species $(\mathrm{pH}<5)$. On the other hand, uranium adsorption decreases in alkaline test solutions because of the higher carbonate concentrations in these solutions. Increased carbonate concentrations lead to desorption of uranium from the solid surface by stabilizing soluble uranium carbonate species (Grenthe et al., 1992). The destabilization of adsorbed uranium in acidic and alkaline solutions can be described by following scheme of equations:

$$
\mathrm{UO}_{2}{ }^{2+}+=\mathrm{S}-\mathrm{OH} \underset{+\mathrm{H}^{+}}{\rightleftharpoons}=\mathrm{S}-\mathbf{O}-\mathrm{UO}_{2}{ }^{+} \stackrel{+2 \mathrm{CO}_{3}{ }^{2-}}{\rightleftharpoons}=\mathrm{S}-\mathrm{O}^{-}+\mathrm{UO}_{2}\left(\mathrm{CO}_{3}\right)_{2}{ }^{2-}
$$

The optimum $\mathrm{pH}$ for the removal of uranium by dunite was found to be $\mathrm{pH} 6.5$ and hence, following investigations were performed at $\mathrm{pH}=6.5$.

\section{The effect of the initial Uranium Concentration}

Figure 2 illustrates the effect of initial uranium concentration on adsorption of uranium on dunite (adsorption isotherms) at various ionic strengths. The experimental data indicate that the amount of uranium uptake is increased as a function of the uranium concentration in solution. The adsorption data, irrespective of the ionic strength, follow the Langmuir isotherm model (Figure 2), indicating that the maximum adsorption capacity is governed by the amount of active sites on the mineral surface. 


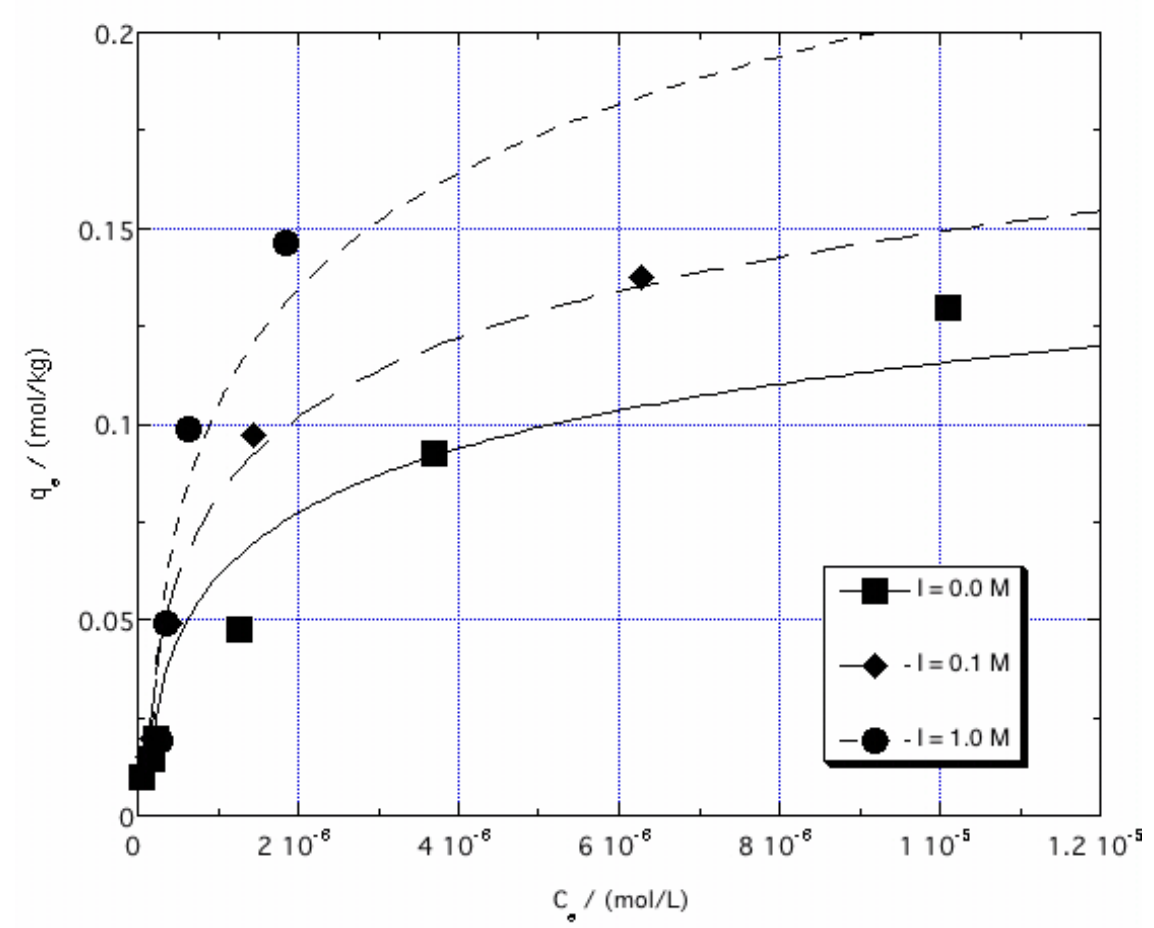

Figure 2. Sorption of uranium on dunite as a function of initial uranium concentration at various ionic strengths

The corresponding Langmuir equation is defined as follows:

$$
\frac{1}{\mathrm{q}}=\frac{1}{\mathrm{q}_{\max } \cdot \mathrm{K}_{\mathrm{L}} \cdot \mathrm{C}_{\mathrm{e}}}+\frac{1}{\mathrm{q}_{\max }}
$$

where $\mathrm{q}_{\max }$ is the maximum adsorption capacity corresponding to complete monolayer coverage $\left(\mathrm{mol} \mathrm{kg}^{-1}\right), \mathrm{K}_{\mathrm{L}}$ is the Langmuir constant related to the energy of adsorption and $\mathrm{C}_{\mathrm{e}}$ is the equilibrium concentration of the adsorbate in solution. Evaluation of the data showed no significant difference between the Langmuir parameters corresponding to solutions of different salinity. The mean values of $\mathrm{q}_{\max }\left(\mathrm{mol} \mathrm{kg}^{-1}\right)$ and $\log \mathrm{K}_{\mathrm{L}}$ were calculated to be $0.07 \pm 0.03$ and 6.4 , respectively.

\section{The effect of the amount of adsorbent}

In Figure 3 the adsorbate amount is expressed in moles uranium (logarithmic scale) per mass of the adsorbent (logarithmic scale). Increasing the adsorbent concentration results in a linear increase in the uranium adsorption, indicating on the formation of inner-sphere complexes. The curves corresponding to the solutions of different salinity are identical and point out similar adsorption mechanism in solutions of different salinity. Furthermore, the absence of any significant effect of the ionic strength on the adsorption efficacy is characteristic for the formation of inner-sphere complexes. Furthermore, according to the data in Figure 3, the saturation of the adsorbent surface is reached when the amount of adsorbed uranium is almost equal to amount of the active sites of the surface. This is a clear indication on a 1:1 surface complex formation 


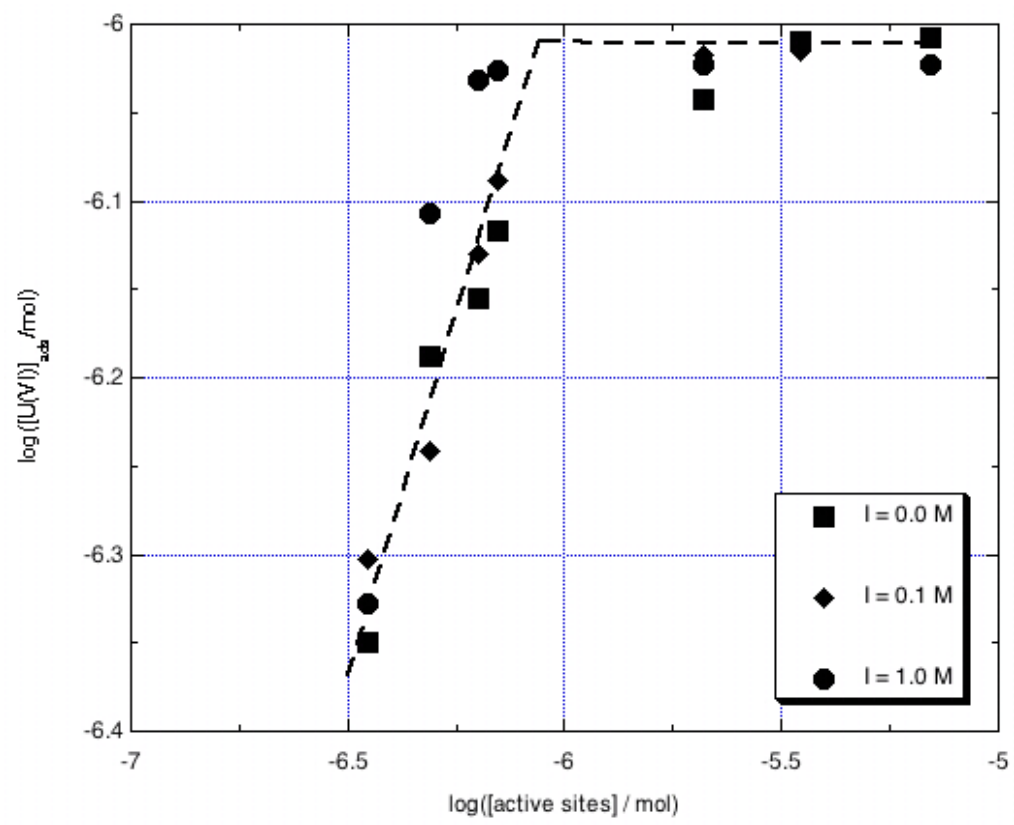

Figure 3. $\log ([\mathrm{U}(\mathrm{VI})])$ as a function of log (mass adsorbent $)$ for the uranium adsorption onto dunite at various ionic strengths

According to literature data on uranium hydrolysis, $\mathrm{UO}_{2}(\mathrm{OH})^{+}$predominates at $\mathrm{pH} 6.5$ among the soluble monomeric species of hexavalent uranium (Grenthe et al., 1992). Hence, the equation for the adsorption reaction could be formulated as:

$$
\mathrm{UO}_{2} \mathrm{OH}^{+}+\equiv \mathrm{SO}^{-} \longleftrightarrow \equiv \mathrm{SOUO}_{2} \mathrm{OH}
$$

The equilibrium constant of the above reaction is given by following equation:

$$
\mathrm{K}=\frac{\left[\equiv \mathrm{SOUO}_{2} \mathrm{OH}\right]}{\left[\equiv \mathrm{SO}^{-}\right] \cdot\left[\mathrm{UO}_{2} \mathrm{OH}^{+}\right]}
$$

where $\left[\mathrm{UO}_{2} \mathrm{OH}^{+}\right]$corresponds to the concentration of uranium in solution, $\left[=\mathrm{SOUO}_{2} \mathrm{OH}\right]$ equals to the amount of adsorbed uranium and [ $\left.=\mathrm{SO}^{-}\right]$equals to the amount of non-occupied surface sites, which are available for uranium complexation and correspond to the $q_{\max }$ value of the Langmuir isotherm. When $\mathrm{q}_{\max }$ is much higer than [ $=\mathrm{SOUO}_{2} \mathrm{OH}$, the equilibrium constant $(K)$ equals to the linear distribution coefficient $\left(K_{d}\right)$, which is a key constant used in contaminant dispersion models.

\section{The effect of temperature}

The temperature dependence of uranium adsorption on dunite was investigated to evaluate the thermodynamical parameters $\left(\Delta G^{\circ} . \Delta \mathrm{H}^{\circ}\right.$ and $\left.\Delta S^{\circ}\right)$ of the adsorption reaction based on following equations:

$$
\begin{gathered}
\Delta \mathrm{G}^{\circ}=-\mathrm{R} \cdot \mathrm{T} \cdot \ln \mathrm{K} \\
\log \mathrm{K}=\frac{\Delta \mathrm{S}^{\circ}}{2.303 \cdot \mathrm{R}}-\frac{\Delta \mathrm{H}^{\circ}}{2.303 \cdot \mathrm{R} \cdot \mathrm{T}}
\end{gathered}
$$

where $T$ is temperature in Kelvin, $R$ is the gas constant and $K$ is the equilibrium constant of the adsorption reaction. The graphical presentation of the van't Hoff plot is shown in Figure 4 and the thermodynamical data evaluated are summarized in Table 1. The values for $\Delta H^{\circ}$ and $\Delta S^{\circ}$ were obtained from the slop and the intercept of log $\mathrm{K}$ vs $1 / T$. The positive value of $\Delta \mathrm{H}$ shows that the adsorption of uranium is endothermic. However, adsorption of uranium on dunite is a spontaneous, entropy-driven process. The large and positive value of $\Delta S$ originates from the metal ion dehydration due to surface sorption. 


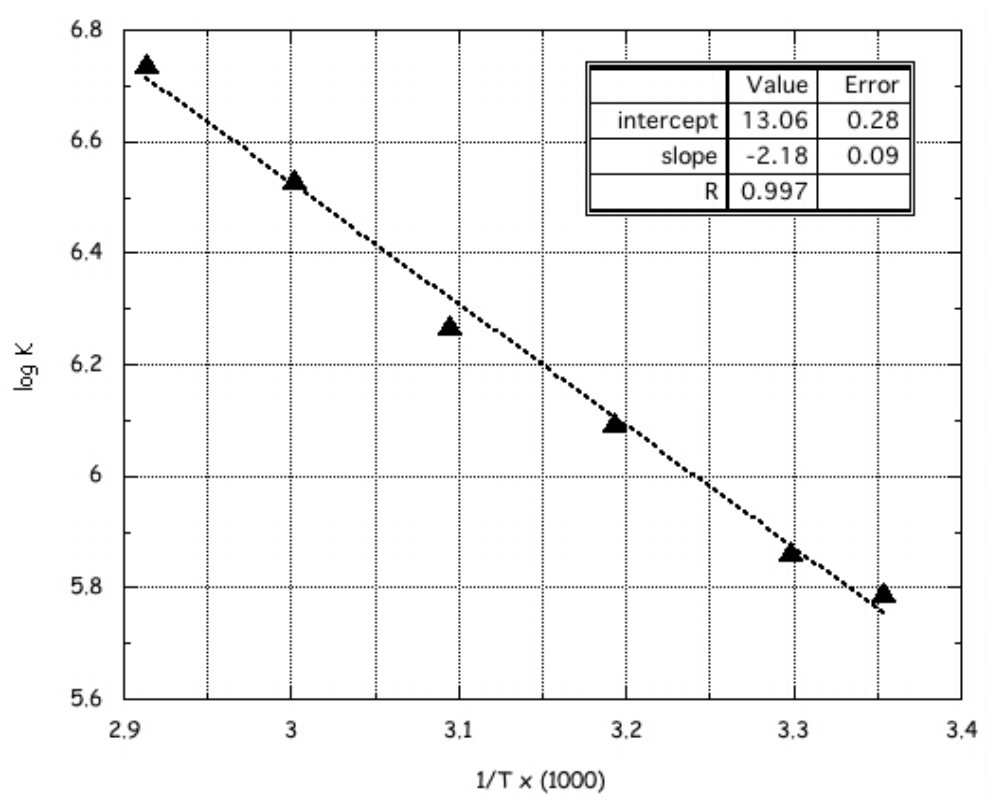

Figure 4. Effect of temperature on uranium adsorption on dunite

Table 1. Thermodynamic parameters for the adsorption on dunite as a function temperature

\begin{tabular}{|c|c|c|c|c|c|c|c|}
\hline$\Delta \mathrm{H}^{\circ}$ & $\Delta \mathrm{S}^{\circ}$ & \multicolumn{6}{|c|}{$\Delta \mathrm{G}^{\circ}(\mathrm{KJ} / \mathrm{mol})$} \\
\cline { 3 - 8 }$(\mathrm{kJ} / \mathrm{mol})$ & $(\mathrm{J} / \mathrm{K} . \mathrm{mol})$ & $298 \mathrm{~K}$ & $303 \mathrm{~K}$ & $313 \mathrm{~K}$ & $323 \mathrm{~K}$ & $333 \mathrm{~K}$ & $343 \mathrm{~K}$ \\
\hline $41.7 \pm 2$ & $250 \pm 5$ & -32.8 & -34.1 & -36.6 & -39.1 & -41.6 & -44.1 \\
\hline
\end{tabular}

\section{The effect of contact time}

Figure 5 shows the relative amount of adsorbed uranium as a function of time under atmospheric conditions, $\mathrm{pH} 6.5$ and $\mathrm{I}=0.0 \mathrm{M}$ (without background electrolyte). According to Figure 5 the adsorption of uranium on dunite occurs in two steps, indicating that adsorption of uranium on dunite takes place as well on the external as on the internal surface of the adsorbent. In first rapid step, which is completed within 100 minutes, almost $70 \%$ of the total uranium is adsorbed. After the second step, which is somewhat slower and is completed at about 500 minutes, the adsorption process is completed and the equilibrium corresponds to $95 \%$ adsorption efficiency. This suggests that the bonding of uranyl ion to active sites occurs preferably on the solid surface, with restricted ion diffusion towards the internal surface of the particles. The latter can be attributed to the relatively small internal surface area of the adsorbent, which is about $6 \mathrm{~m}^{2} \mathrm{~g}^{-1}$.

The kinetics of uranium adsorption on dunite regarding the first step follows the first order rate expression given by Lagergren (Namasivayam and Senthilkumar, 1998). The apparent $\mathrm{k}_{\mathrm{ad}}$ value evaluated at $25^{\circ} \mathrm{C}$ and $\mathrm{pH} 6.5$ is found to be about $3.0 \times 10^{-3} \mathrm{~min}^{-1}$ for solutions of $\mathrm{I}=0$ $\mathrm{M}$ and $\mathrm{I}=0.1 \mathrm{M}$.

\section{CONCLUSIONS}

The results obtained from this study lead to the following conclusions: (a) the optimum $\mathrm{pH}$ for uranium removal by dunite is $\mathrm{pH} 6.5$, (b) the experimental data can be fitted by the Langmuir isotherm, (c) there is a linear correlation between adsorbent mass and amount of uranium which does not depend on the ionic strength, indicating on the formation of inner-sphere complexes and (d) the adsorption of $\mathrm{U}(\mathrm{VI})$ on dunite is an endothermic, entropy-driven process and follows a first order rate expression. 


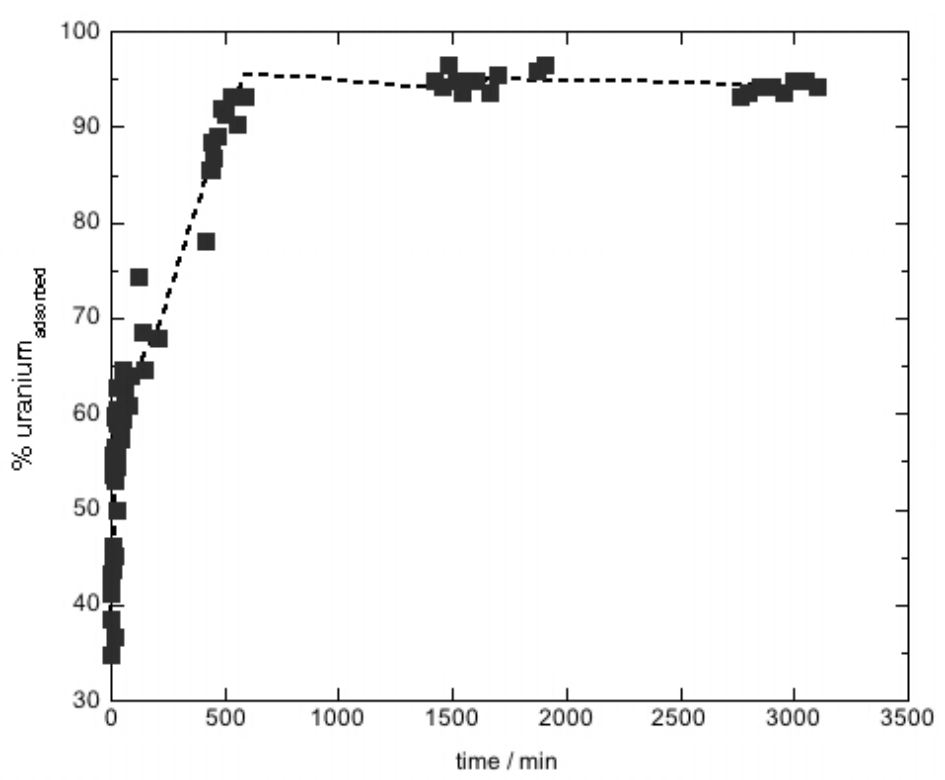

Figure 5. Effect of time of contact on uranium adsorption on dunite

\section{REFERENCES}

Aksoyoglu S. (1989) Sorption of U(VI) on granite, Journal of Radioanalytical and Nuclear Chemistry, 134(2), 393-403.

Ames L.L., Mc-Garrah J.E., Walker B.A. and Salter P.F. (1983), Uranium and Radium sorption on amorphous ferric oxyhydroxide, Chemical Geology, 40, 135-148.

Arnold T., Zorn T., Bernhard G. and Nitsche H. (1998) Sorption of uranium(VI) onto phyllite, Chemical Geology, 151, 129-141.

Blázquez G., Hernáinz F., Calero M., Ruiz-Núñez L.F. (2005) Removal of cadmium ions with olive stones: the effect of somes parameters, Process Biochemistry, 40, 2649-2654.

Bleise A., Danesi P.R. and Burkart W. (2003) Properties, use and health effects of depleted uranium (DU): a general overview, Journal of Environmental Radioactivity, 64, 93-112.

Donat R. and Aytas S. (2005) Adsorption and thermodynamic behavior of uranium(VI) on Ulva sp.$\mathrm{Na}$ bentonite composite, Journal of Radioanalytical and Nuclear Chemistry, 265(1), 107114.

Grenthe I., Fuger J., Konings M., Lemire R.J., Muller A.B., Nguyen-Trung Gregu C. and Wanner H. (1992) Chemical Thermodynamics of Uranium, Elsevier, New York.

Hongxia Z. and Zuyi T. (2002) Sorption of uranyl ions on silica: Effects of contact time, pH, ionic strength, concentration and phosphate, Journal of Radioanalytical and Nuclear Chemistry, 254(1), 103-107.

Kilincarslan A. and Akyil S. (2005) Uranium adsorption characteristic and thermodynamic behavior of clinoptilolite zeolite, Journal of Radioanalytical and Nuclear Chemistry, 264(3), 541-548.

Namasivayam C. and Senthilkumar S. (1998) Removal of Arsenic(V) from Aqueous Solution Using Industrial Solid Waste: Adsorption Rates and Equilibrium Studies, Industrial \& Engineering Chemistry Research, 37, 4816-4822.

Savvin S.B. (1961) Analytical use of Arsenazo III, Talanta, 8, 673.-685.

Shawky S., Abdel-Geleel M. and Aly A. (2005), Sorption of uranium by non-living water hyacinth roots, Journal of Radioanalytical and Nuclear Chemistry, 265(1), 81-84.

Waite T.D., Davis J.A., Payne T.E., Waychunas G.A. and Xu N. (1994) Uranium(VI) adsorption to ferrihydrite: Application of a surface complexation model, Geochimica et Cosmochimica Acta, 58(24), 5465-5478.

Wersin P., Hochella M.F., Persson P., Redden G., Leckie J.O. and Harris D.W. (1994) Interaction between aqueous uranium (VI) and sulfide minerals: Spectroscopic evidence for sorption and reduction, Geochimica et Cosmochimica Acta, 58(13), 2829-2843. 
Zhijun G., Zhaoyun Y. and Zuyi T. (2004) Sorption of uranyl ions on $\mathrm{TiO}_{2}$ : Effects of contact time, ionic strength, concentration and humic substance, Journal of Radioanalytical and Nuclear Chemistry, 261(1), 157-162.

Zuyi T., Taiwei C., Jinzhou D., XiongXin D. and Yingjie G. (2000) Effect of fulvic acids on sorption of $\mathrm{U}(\mathrm{VI}), \mathrm{Zn}, \mathrm{Yb}, \mathrm{I}$ and $\mathrm{Se}(\mathrm{IV})$ onto oxides of aluminum, iron and silicon, Applied Geochemistry, 15, 133-139. 